\title{
HIGHER-RANK NUMERICAL RANGES \\ OF UNITARY AND NORMAL MATRICES
}

\author{
MAN-Duen ChOI, JoHn A. HOLBROOK, \\ DAVID W. KRIBS AND KAROL ŻYCZKOWSKI
}

\begin{abstract}
We verify a conjecture on the structure of higher-rank numerical ranges for a wide class of unitary and normal matrices. Using analytic and geometric techniques, we show precisely how the higher-rank numerical ranges for a generic unitary matrix are given by complex polygons determined by the spectral structure of the matrix. We discuss applications of the results to quantum error correction, specifically to the problem of identification and construction of codes for binary unitary noise models.
\end{abstract}

Mathematics subject classification (2000): 15A60, 15A90, 47A12, 81P68.

Key words and phrases: Higher-rank numerical range, unitary matrix, quantum error correction.

\section{REFERENCES}

[1] R. ALICKI AND K. LENDI, Quantum dynamical semigroups and applications, Springer-Verlag, Berlin, (1987).

[2] H. BARNUM, E. KNILL, Reversing quantum dynamics with near-optimal quantum and classical fidelity, J. Math. Phys. 43(2002), 2097.

[3] I. BENGTSSON AND K. ŻYCZKOwsKi, Geometry of quantum states, Cambridge University Press (2006).

[4] M. D. CHOI, M. GIESINGER, J. A. HolBROOK AND D. W. KRIBS, Geometry of higher-rank numerical ranges, preprint, 2007.

[5] M. D. CHOI, D. W. KRIBS AND K. ŻYCZKOWSKI, Quantum error correcting codes from the compression formalism, Rep. Math. Phys. 58 (2006), 77-86.

[6] M. D. ChOI, D. W. KRIBS AND K. ŻYCZKOWSKI, Higher-rank numerical ranges and compression problems, Lin. Alg. Appl., 418 (2006), 828-839.

[7] C. CREPEAU, D. GOTTESMAN AND A. SMITH, Approximate quantum error-correcting codes and secret sharing schemes, quant-ph/0503139.

[8] D. R. FARENICK, Matricial extensions of the numerical range: A brief survey, Linear and Multilinear Algebra 34 (1993), 197-211.

[9] P. Halmos, A Hilbert space problem book, D. Van Nostrand Company, Ltd., Toronto, (1967).

[10] E. KNILl AND R. LAFLAMME, A theory of quantum error-correcting codes, Phys. Rev. A 55 (1997), 900.

[11] D. KRIBS, R. LAFLAMME AND D. POULIN, Unified and generalized approach to quantum error correction, Phys. Rev. Lett. 94 (2005), 180501.

[12] D. W. KRIBS, R. LAFLAMME, D. POULIN AND M. LESOSKY, Operator quantum error correction, Quantum Inf. \& Comp. 6 (2006), 382.

[13] S. R. LAY, Convex sets and their applications, John Wiley \& Sons, (1982).

[14] D. W. LeUnG, M. A. NielSEN, I. L. ChUANG AND Y. YAMAMOTO, Approximate quantum error correction can lead to better codes, Phys. Rev. A 56 (1997), 2567.

[15] C.-K. LI AND N.-S. SZE, Canonical forms, higher rank numerical ranges, totally isotropic subspaces, and matrix equations, (preprint)

[16] C.-K. LI, Y.-T. POON AND N.-S. SZE, Condition for the higher rank numerical range to be non-empty, (preprint) 
[17] C.-K. Li AND N.-K. Tsing, On the k th matrix numerical range, Linear and Multilinear Algebra 28 (1991), 229-239.

[18] B. SCHUMACHER, M. D. WeStMORELAND, Approximate quantum error correction, quant-ph/0112106.

[19] H. WOERDEMAN, The higher rank numerical range is convex, Linear and Multilinear Algebra, to appear. 